Bulletin d'Histoire Contemporaine de l'Espagne

$51 \mid 2017$

Les forces politiques durant la Seconde République espagnole

\title{
El fracaso de la reforma agraria en las Cortes de la Segunda República
}

L'échec de la réforme agraire aux Cortès de la Seconde République Espagnole The failure of the agrarian reform in the Cortes of the Spanish Second Republic

Miguel Ángel Giménez Martínez

(2) OpenEdition Journals

Edición electrónica

URL: http://journals.openedition.org/bhce/741

DOI: 10.4000/bhce.741

ISSN: 1968-3723

Editor

Presses Universitaires de Provence

Edición impresa

Fecha de publicación: 1 junio 2017

Paginación: 197-217

ISSN: 0987-4135

Referencia electrónica

Miguel Ángel Giménez Martínez, «El fracaso de la reforma agraria en las Cortes de la Segunda República », Bulletin d'Histoire Contemporaine de l'Espagne [En línea], 51 | 2017, Publicado el 09 octubre 2018, consultado el 19 abril 2019. URL : http://journals.openedition.org/bhce/741 ; DOI : 10.4000/ bhce.741 


\title{
El fracaso de la reforma agraria en las Cortes de la Segunda República
}

\author{
Miguel Ángel GIMÉNEZ MARTíNEZ
}

Universidad de Castilla-La Mancha

1 proclamarse la Segunda República, una de las cuestiones que con mayor urgencia
se planteaban era la de la reforma agraria. Las actividades agropecuarias eran, en
abril de 1931, el elemento principal de la estructura socioeconómica de España. El porcentaje de personas que vivían en zonas rurales y dependían económicamente de las actividades agrarias superaba el $50 \%$. Más de cuatro millones de españoles, de una población activa de ocho millones y medio, se empleaban en este sector, que aportaba casi la tercera parte de la producción total ${ }^{1}$. No es extraño, por tanto, que, en un país con aquellas características y ante las expectativas elevadas por el cambio político, fuera inevitable afrontar desde el primer momento el gran problema socioeconómico del momento.

La agricultura planteó tres problemas, interrelacionados entre sí, a los nuevos dirigentes republicanos: en primer lugar, un elevado desempleo campesino, sobre todo en el sur del país; en segundo, la concentración de la propiedad de la tierra en torno a pocas manos y las consecuencias derivadas de este hecho; y, por último, la reducida productividad de las explotaciones agrarias ${ }^{2}$. Habría que añadir a estos tres, además, la enorme carga de conflictividad social y política que portaban en su interior. Por tanto, la llamada reforma agraria iría dirigida hacia la consecución de tres objetivos: acabar con el paro, repartir mejor la tierra y aumentar el rendimiento de las explotaciones ${ }^{3}$. En este sentido, la República

1 Gabriel Tortella y Clara Eugenia NúNez, El desarrollo de la España contemporánea. Historia económica de los siglos $X I X$ y XX, $3^{\text {a }}$ ed., Madrid, Alianza, 2011, p. 334-336; y Grupo de Estudios de Historia Rural (GEHR), (El sector agrario hasta 1935», en Albert CARRERAs (coord.), Estadísticas históricas de España. Siglos XIX-XX, Madrid, Fundación Banco Exterior, 1989, p. 92-129. Sobre la situación social y económica de España al advenimiento de la República, vid. Leandro BENAVIDEs, La politica económica en la Segunda República, Madrid, Guadiana, 1972; Ramón TAmames, Estructura económica de España. Vol. I: Introducción y sector agrario, Madrid, Guadiana, 1974; Salustiano DeL. CAMPO, «Composición, dinámica y distribución de la población española», en Manuel FraGA IRIBARNE et al, La España de los años 70. Vol. I: La sociedad, Madrid, Moneda y Crédito, 1974, p. 15-145; y Jordi Pal afox, Atraso económico y democracia: la Segunda República y la economia española, 1892-1936, Madrid, Crítica, 1991.

2 Las dos obras clásicas para conocer la situación del campo español al proclamarse la Segunda República son las de Pascual Carrión, Los latifundios en España: su importancia, origen, consecuencias y solución, Madrid, Gráficas Reunidas, 1932 (con prólogo de Fernando de los Ríos), y Edward MALEFAKIs, Reforma agraria y revolución campesina en la España del siglo XX, Barcelona, Ariel, 1971. Vid. también Jacques MaURICE, La reforma agraria en España en el siglo XX (1900-1936), Madrid, Siglo XXI, 1975.

3 Cfr. las finalidades mencionadas por el ministro de Agricultura, Marcelino DomisGo, en Diario de Sesiones de las Cortes Constituyentes (DSCC), $\mathrm{n}^{\circ} 183,15$ de junio de 1932, p. 6.214-6.218, donde puso fin al debate sobre la totalidad del proyecto de Ley de Reforma Agraria. 
significó, como ha afirmado Malefakis, el primer intento serio de la historia de España de cambiar la situación secular del agro ${ }^{4}$.

Se desconoce si los grupos políticos que integraron el Gobierno provisional llegaron a un acuerdo previo sobre la cuestión agraria y tampoco se sabe si trataron el tema antes del 14 de abril de 1931. El hecho es que en su Estatuto jurídico se acudió a una fórmula muy amplia, que se limitaba a afirmar el respeto por la propiedad privada y la intención de introducir cambios en el Derecho agrario vigente ${ }^{5}$. Poco después, el Gobierno provisional acordó que las futuras Cortes Constituyentes se encargaran de adoptar las medidas pertinentes sobre la reforma agraria $^{6}$. Sin embargo, el Ejecutivo presidido por Niceto Alcalá-Zamora tomó durante su mandato dos decisiones que se revelarían trascendentales: en primer término, una serie de decretos impulsados por el ministro de Trabajo, el socialista Francisco Largo Caballero, que modificaron sustancialmente las condiciones de trabajo en el campo ${ }^{7}$; y, en segundo, la creación de una Comisión Técnica, a la que se encargó proponer la estructura normativa sobre la que tendría que pivotar la reforma. En julio de 1931, la Comisión ultimó un primer proyecto, que se ceñía al problema de los latifundios del sur y recomendaba su entrada en vigor por decreto ${ }^{8}$. La oposición manifestada por el PRR (Partido Republicano Radical) y el PSOE (Partido Socialista Obrero Español), por razones distintas, determinó que el Consejo de Ministros lo desestimara9. Sin embargo, este proyecto terminaría convirtiéndose en el punto de referencia sobre el que acabaría construyéndose la reforma agraria.

A partir de ese momento, el protagonismo correspondería a las Cortes. En la Legislatura Constituyente (1931-1933) se celebraron en la Cámara tres debates importantes relacionados con el problema agrario: el que se produjo con motivo del artículo 44 de la Constitución, en el que quedaban estipuladas las competencias del Estado respeto de la propiedad privada ${ }^{10}$; el que tuvo lugar en la primavera y el verano de 1932 para la aprobación de la Ley de Reforma Agraria ${ }^{11}$, y, finalmente, el que se desarrolló en torno al proyecto de Ley de

4 Edward Malefakis, Reforma agraria, op. cit., p. 20.

5 Según la declaración quinta del Estatuto (Gaceta de Madrid, n 105, 15 de abril de 1931, p. 195): «El Gobierno provisional declara que la propiedad privada queda garantizada por la ley; en consecuencia, no podrá ser expropiada sino por causa de utilidad pública y previa indemnización correspondiente. Mas este Gobiemo, sensible al abandono absoluto en que ha vivido la inmensa masa campesina española, al desinterés de que ha sido objeto la economía agraria del país y a la incongruencia del derecho que la ordena con los principios que inspiran y deben inspirar las legislaciones actuales, adopta como norma de su actuación el reconocimiento de que el derecho agrario debe responder a la función social de la tierra».

6 Edward MaLefakis, Reforma agraria, op. cit., p. 199.

7 En ibídem, p. 200-206, se puede encontrar un buen resumen de los decretos de Largo Caballero, de sus implicaciones y de las reacciones que provocaron. Una perspectiva jurídica la ofrece Luis Enrique DE LA VILLA, «El derecho del trabajo en España, durante la Segunda República», en Revista de la Facultad de Derecho de la Universidad de Madrid, vol. XIII, n 34-36, 1969, p. 237-270.

8 La Comisión Técnica Agraria fue creada por decreto del Ministerio de Justicia en mayo de 1931 (Gaceta de Madrid, $\mathrm{n}^{\circ}$ 142, 22 de mayo de 1931, p. 863). De ella se formó una Subcomisión-compuesta por Felipe Sánchez-Román (presidente de la Comisión), los ingenieros agrónomos Pascual Carrión y Eduardo Rodrigáñez, y los economistas Antonio Flores de Lemus, y Agustín Viñuales-, encargada de estudiar el problema de los latifundios. Las bases del proyecto que la Subcomisión presentó al Gobierno pueden consultarse en Pascual CARrión, Los latifundios en España, op. cit., p. 421-432.

- Pascual CARRIón, La reforma agraria de la Segunda República y la situación actual de la agricultura española, Barcelona, Ariel, 1973, p. 117-118. Sobre los debates en el seno del Gobierno en torno a la reforma agraria, vid. Manuel AzAña, Memorias politicas y de guerra. Vol. IV: Obras Completas, México, Oasis, 1968 , p. 36, 40 y $75-77$.

10 DSCC, $\mathrm{n}^{\circ} 50$ y 51,6 y 7 de octubre de 1931 , p. $1.430-1.492$.

11 Gaceta de Madrid, $\mathrm{n}^{\circ} 265,21$ de septiembre de 1932, p. 2.095-2.102. DSCC, $\mathrm{n}^{\circ}$ 162-233, 10 de mayo - 9 de septiembre de 1932 , p. 5.481-8.719. 
Arrendamientos Rústicos, que quedó inconcluso por la crisis gubernamental de septiembre de 1933 y la subsiguiente convocatoria anticipada de elecciones ${ }^{12}$.

En la siguiente Legislatura (1933-1935), la primera intervención de las Cortes tuvo que ver con la derogación de la Ley de Términos Municipales, la más polémica norma y la que más oposiciones había generado de las impulsadas por Largo Caballero ${ }^{13}$. Casi a la vez, se discutió y aprobó una ley para engrandecer la superficie cultivable en Extremadura ${ }^{14}$. A finales de 1934, el ministro de Agricultura, Manuel Giménez Fernández, anunció una serie de proyectos, de los que el Parlamento solo llegaría a aprobar la Ley de Yunteros ${ }^{15} \mathrm{y}$ la de Arrendamientos ${ }^{16}$. Su sucesor en el cargo, Nicasio Velayos, presentó en el verano de 1935 una modificación sustancial de la Ley de Reforma Agraria, que salió adelante tras un breve debate ${ }^{17}$.

En la Legislatura de 1936, Mariano Ruiz-Funes trató de actuar enérgica y rápidamente. Junto a las medidas urgentes aprobadas por el Gobierno del Frente Popular, destinadas a encauzar el problema de las ocupaciones ilegales de tierras, el nuevo ministro presentó ante el Parlamento un conjunto de proyectos de ley, de los cuales solo se aprobaron los relativos a la revisión de desahucios ${ }^{18} \mathrm{y}$ a la reposición de la Ley de Reforma Agraria de $1932^{19}$. Cuando las Cortes fueron suspendidas en julio de 1936, dias antes del estallido de la Guerra Civil, se estaba discutiendo un texto que permitiría a los municipios recuperar los bienes comunales ${ }^{20}$.

Esta fue, resumidamente, la actividad desplegada por las Cortes republicanas en materia agraria y esta será, en consecuencia, la materia del análisis que se plantea en este artículo ${ }^{21}$.

Si se hace recuento de lo hecho entre abril de 1931 y julio de 1936 , se llega a la sencilla conclusión de que los términos del problema agrario no sufrieron prácticamente alteración.

12 Vid. el proyecto de ley en DSCC, ap. $3^{\circ}$ al $n^{\circ} 324,6$ de abril de 1933. Los debates en DSCC, $\mathrm{n}^{\circ} 378-$ 402, 27 de julio - 7 de septiembre de 1933, p. 14.443-15.382. Además, en el verano de 1933, Marcelino Domingo presentó otros proyectos, uno sobre creación del Banco Agrario y otro sobre la restitución de tierras comunales a los municipios.

13 Gaceta de Madrid, $\mathrm{n}^{\circ} 150,30$ de mayo de 1934, p. 1.387. Diario de las Sesiones de Cortes (DSC), $\mathrm{n}^{\circ}$ 29-88, 26 de enero - 24 de mayo de 1934, p. 717-3.132.

14 Gaceta de Madrid, $\mathrm{n}^{\circ} 47,16$ de febrero de 1934, p. 1.274-1.275. DSC, $\mathrm{n}^{\circ} 31-38,31$ de enero - 20 de febrero de 1934, p. 800-1.039.

15 Gaceta de Madrid, $\mathrm{n}^{\circ} 363,29$ de diciembre de 1934, p. 2.540. DSC, $\mathrm{n}^{\circ} 125-143,21$ de noviembre - 20 de diciembre de 1934, p. 4.907-5.663.

16 Gaceta de Madrid, $\mathrm{n}^{\circ} 83,24$ de marzo de 1935, p. 2.346-2.351. DSC, $\mathrm{n}^{\circ} 133-171,5$ de diciembre de 1934 - 14 de marzo de 1935 , p. 5.263-6.944. Las Cortes aprobaron también otro proyecto (Gaceta de Madrid, $\mathrm{n}^{\circ} 90,31$ de marzo de 1935, p. 2.532-2.533), de menor importancia, sobre los baldios de Alburquerque (Badajoz). DSC, $\mathrm{n}^{\circ} 176,3$ de mayo de 1934, p. 7.176-7.183,

17 Gaceta de Madrid, $\mathrm{n}^{\circ} 222,10$ de agosto de 1935, p. 1.288-1.291. DSC, n 227-231, 20 - 26 de julio de 1935 , p. $9.320-9.520$.

18 Gaceta de Madrid, $\mathrm{n}^{\circ} 156,4$ de junio de 1936, p. 2.019-2.020. DSC, $\mathrm{n}^{\circ} 31-35,21-28$ de mayo de 1936, p. 794-964.

19 Gaceta de Madrid, $\mathrm{n}^{\circ} 171,19$ de junio de 1936, p, 2.478. DSC, $\mathrm{n}^{\circ} 34$ y 35, 27 y 28 de mayo de 1936, p. 913-962.

20 DSC, $\mathrm{n}^{\circ}$ 52-60, 26 de junio - 10 de julio de 1936, p. 1.663-2.067.

21 No nos proponemos entrar a fondo en el contenido de la cuestión agraria, lo que ya han hecho con mérito varios autores expertos en historia económica y rural como Ricardo Robledo, "Politica y reforma agraria: de la Restauración a la $\Pi^{3}$ República (1868/74-1939)"), en Ángel Garcta SANz y Jesús SANZ FERnÁndez (eds.), Reformas politicas y agrarias en la historia de España, Madrid, Ministerio de Agricultura, 1996, p. 247-349; o Ramón Garrabou, Carlos Barciela y José Ignacio Jiménez Blanco (eds.), Historia agraria de la España contemporánea. 3. El fin de la agricultura tradicional (1900. 1960), Barcelona, Crítica, 1986. 
Al contrario, la intensificación de los conflictos políticos en torno a ellos los agravó. Por esta razón, se puede afirmar el fracaso de la política agraria de la Segunda República, pues no logró ninguno de sus objetivos, cifrados en la modernización social y económica del campo. Normalmente, para explicar este fracaso se ha apuntado a la inestabilidad, parálisis y contradicciones que atenazaron a los diferentes Gobiernos. Este trabajo, sin embargo, no se centrará en esta cuestión, sino en el proceso en virtud del cual las distintas medidas reformistas se gestaron en las Cortes, que determinó la virtualidad de las mismas y demostró, incluso antes de su aplicación, su incapacidad para resolver los problemas planteados.

Nos proponemos observar el comportamiento de los partidos con presencia parlamentaria en torno a la cuestión agraria. Al no haber durante la Segunda República un eje derechaizquierda, entendido según criterios socioeconómicos, que constituyera la divisoria más importante dentro del sistema de partidos ${ }^{22}$, las diferentes fuerzas y bloques políticos carecieron de una línea coherente en sus programas socioeconómicos, lo que dificultó que cumplieran con eficacia su función de «agregación de intereses» ${ }^{23}$. De este modo, se complicaría en extremo la posibilidad de que se articularan alternativas adecuadas a un problema de tal calado. A la inversa, puede concluirse también que dichas alternativas, al no coincidir con las líneas de división políticas, estuvieron sometidas a una serie de tensiones que terminaron por hacer inviable cualquier proyecto. Esto fue lo que ocurrió, una y otra vez, con la estrategia que más veces trató de ponerse en práctica-quizá la única posible en aquellas circunstancias- durante la Segunda República: acometer reformas legislativas graduales que no pusieran en cuestión la estructura económica vigente. A continuación veremos cómo la fragmentación, la dispersión y, en ocasiones, el enfrentamiento de grupos políticos que coincidían en sus planteamientos de cambio social y económico, impidieron que culminara con éxito una eficaz reforma agraria.

\section{La frustración de la estrategia reformista}

La única vía que se emprendió durante la Segunda República para atajar el problema agrario fue la reformista. Lo que no es extraño si se tiene en cuenta que entre los partidos políticos existía una mayoría, situada en la franja central del espectro político, que abarcaba por la izquierda a un amplio sector del socialismo y por la derecha a los llamados socialcristianos. De este modo, ministros de Agricultura pertenecientes a partidos distintos, desde el radical-socialista Marcelino Domingo hasta el republicano de izquierdas Mariano Ruiz-Funes, pasando por el progresista Cirilo del Río o el cedista Manuel

22 Sobre las diversas fuerzas políticas y el sistema de partidos en la Segunda República, vid. Juan José Linz, El sistema de partidos en España, Madrid, Narcea, 1974, p. 109 y ss.; Richard GunTHER, Giacomo Sant y Goldie SHABAD, El sistema de partidos politicos en España. Génesis y evolución, Madrid, Centro de Investigaciones Sociológicas, 1986, p. 14-23; los artículos de Luis Arranz Notario, «Modelos de partido» y Santos JuliÁ, "Sistema de partidos y problemas de consolidación de la democracia», publicados en Santos Jultá (ed.), Politica en la Segunda República. Ayer, n²0, 1995, p. 81-110 y 111 141; Manuel Álvarez TArdío, «Las Cortes de la Segunda República: ¿un Parlamento de Partidos?», en Revista de las Cortes Generales, n 63, 2004, p. 139-173; Ignacio Fernández Sarasola, Los partidos politicos en el pensamiento español. De la Ilustración a nuestros dias, Madrid, Marcial Pons, 2009, p. 245-281, y Fernando del Rey Regulllo (dir.), Palabras como puños. La intransigencia politica en la Segunda República, Madrid, Tecnos, 2011.

23 Sobre el concepto de «agregación de intereses», vid. Manuel RaMírez, Los grupos de presión en la Segunda Repuiblica española, Madrid, Tecnos, 1969, y, resumen de esta obra, su artículo «La agregación de intereses en la II República: partidos y grupos), en Manuel Ramírez et al., Estudios sobre la II Repiblica, Madrid, Tecnos, 1975, p. 25-46. 
Giménez Fernández, representaron la misma política, en la que inspiraron esencialmente sus respectivos proyectos.

Poco antes de estallar la Guerra Civil, cuando se acusaba al Gobierno de impulsar una política revolucionaria en el agro español, Ruiz-Funes precisó en las Cortes que el alcance auténtico de sus proyectos no hacía sino continuar con el espíritu mantenido por sus antecesores en el cargo desde 1931: «Nuestro deber es eliminar egoísmos; nuestro deber es, llegado el momento, resolver con un criterio de justicia, que no es el viejo mito de la espada, sino el símbolo de una balanza que pesa y mide; nuestro deber es también, en definitiva, inclinarnos por los más débiles. Todo el proteccionismo del Estado se funda en esto, en el concepto de que ha habido clases sociales que por su situación económica no han tenido medios para defenderse, y hay que prestárselos. No vamos a una economía marxista, no vamos a un régimen marxista; vamos, sencillamente, a una situación de justicia que hasta ahora no se había producido ${ }^{24}$. La intervención del Estado dirigida a procurar que la propiedad cumpliera su «función social» y para aumentar la producción agraria concitó una coincidencia prácticamente general en los órganos de decisión republicanos. Una coincidencia manifestada no solo en su contenido, sino también en el procedimiento a seguir, que pasaba por el respeto a los preceptos constitucionales y a la vía parlamentaria, asi como por el carácter gradual de las reformas.

Muchos autores han afirmado que la estrategia reformista fue inadecuada para resolver un problema social y económico tan grande, lo que condenó al fracaso desde el principio. Así, Jackson ha subrayado que «de los principales problemas con que tropezó la República, el único para el que verdaderamente era imposible hallar una solución moderada y legislativa era el de la reforma agraria $\rangle^{25}$. Ramos Oliveira ha hecho notar igualmente la incapacidad de un régimen parlamentario para resolver la cuestión ${ }^{26}$. Murillo Ferrol ha puesto el acento en el desfase entre la política reformista y al estructura social de España en aquella época ${ }^{27}$. Y Malefakis, menos categórico, tras advertir problemas que la reforma agraria democrática no estaba preparada para resolver, ha mostrado su escepticismo sobre el éxito de las medidas republicanas, aun reconociendo que no había otra alternativa realista y que la vía reformista, aplicada de otro modo, podía haber producido resultados distintos ${ }^{28}$.

Tales apreciaciones no tienen en cuenta un problema, a nuestro juicio, fundamental: que para hablar de los limites de la politica reformista socioeconómica, ésta tendría que haberse ejecutado con una mínima vocación de perdurabilidad y efectividad. Sin embargo, la Segunda República no lo consiguió nunca, y no precisamente por no haberlo intentado. Si se analizan las medidas planteadas para remediar la situación del sector agrario español se observa cómo éstas fueron complejas, contradictorias y lentas en su gestación, lo que determinó que su puesta en vigor fuera a menudo extemporánea. No se trata de que la reforma fuera insuficiente, tímida o careciera de determinación, sino que fue confusa y desordenada. Estaba lleno de razón Jackson al sostener que la Ley de Reforma Agraria de 1932 parecía «pensada por una asociación de abogados sin empleo que deseaban asegurar

24 DSC, $\mathrm{n}^{\circ}$ 54, 1 de julio de 1936, p. 1.762.

25 Gabriel Jackson, La República española y la guerra civil, México, Grijalbo, 1967, p. 399.

26 Antonio Ramos Oliveira, Historia de España, vol. III, México, Compañia General de Ediciones, 1952, p. 93-111.

27 Francisco Murillo Ferrot, «Un balance desde la perspectiva», en Manuel Ramirez et al., Estudios sobre la II República, op. cit., p. 251-264.

28 Edward Malefakis, Reforma agraria, op. cit., p. 21-22 y 442-455. 
no solo a ellos, sino a sus futuros hijos abogados, un medio de ganarse bien la vida, en lugar de ser una ley escrita para los campesinos de España $\rangle^{29}$.

Así pues, antes de entrar a valorar si la República burguesa fue incapaz de solucionar el problema agrario con los instrumentos constitucionales y parlamentarios puestos a su disposición, hay que plantearse si la estrategia reformista se puso verdaderamente en marcha en algún momento. Ya hemos dicho que existía un amplio consenso en torno a la necesidad de abordar la cuestión por la vía de las reformas y que, pese a todas las dificultades, no había otra política viable. Entonces, ¿por qué esa voluntad no se tradujo en medidas coherentes y eficaces?

Para encontrar una respuesta adecuada a esta pregunta hay que mirar a los partidos políticos presentes en las Cortes republicanas y a la poca consistencia de sus programas socioeconómicos. Así, por un lado, las tres alternativas posibles -revolucionara, reformadora y conservadora- se encontraban a la vez en el interior de una misma fuerza política, mientras que, por otra parte, ninguna de ellas se concentraba únicamente en un solo partido, sino que estaban repartidas entre todos ellos. Por tanto, el reformismo como estrategia política estuvo fragmentando en organizaciones diferentes que, muy a menudo y por razones diferentes, estaban enfrentadas entre sí. De forma paralela, en algunos partidos, como el PSOE o la CEDA (Confederación Española de Derechas Autónomas), el reformismo tuvo que competir con otras visiones revolucionarias o conservadoras. Y algo parecido ocurrió en las coaliciones y los bloques, tanto gobernantes como opositores, incluso más agudamente, debido a la heterogeneidad de su composición. Veamos a continuación cómo la necesidad de mantener la unidad de los partidos y las coaliciones hizo que la reforma agraria fuera, a la postre, incoherente e ineficaz.

\section{El bienio republicano-socialista y la postura del PSOE}

Durante la legislatura constituyente, la coalición republicano-socialista quebró su coherencia en torno a la reforma agraria cuando se dieron cita dos circunstancias. Por un lado, que importantes minorías (Agrupación al Servicio de la República, republicanos federales, progresistas, liberal-demócratas y, sobre todo, radicales) de talante reformista se situaran en la oposición al Gobierno. Y, por otro, que el partido más importante de la mayoría gubernamental, el PSOE, que en principio debía ser el más decidido impulsor de los cambios sociales y económicos, se encontrara atenazado por las luchas internas entre los partidarios de la reforma y los de la revolución.

En efecto, la actitud de los socialistas ante la cuestión agraria fue un ejemplo de contradicción ${ }^{30}$. No hubo una doctrina ni una línea definida de actuación sobre esta materia en el $\mathrm{PSOE}^{31}$. De las intervenciones parlamentarias de los diputados socialistas, cuando se

29 Gabriel JACKson, La República española, op. cit., p. 80.

30 De hecho, como ha puesto de relieve Paloma Biglino (El socialismo español y la cuestión agraria, 1890 1936, Madrid, Ministerio de Trabajo y Seguridad Social, 1986), la preocupación por los problemas de la población campesina ocupó tradicionalmente un lugar marginal en el conjunto de la práctica y del ideario socialistas. Para un análisis de conjunto de las contradicciones internas del PSOE durante la Segunda República es interesante el artículo de Manuel Contreras, «El partido socialista: análisis de un conflicto internoy, en Manuel Ramirez et al., Estudios sobre la II República, op. cit., p. 201-215. Del mismo autor, un estudio más amplio es su libro El PSOE en la II República: organización e ideologia, Madrid, Centro de Investigaciones Sociológicas, 1981.

31 En el Congreso extraordinario del PSOE que tuvo lugar en julio de 1931, con el objeto de fijar la actitud que los diputados socialistas debían adoptar en las Cortes Constituyentes, las posiciones en torno a la 
discutió la Ley de Reforma Agraria de 1932, no es posible extraer el programa socialista para la agricultura. Éstos insistirian en mostrar un perfil posibilista y dispuesto a la transacción a lo largo de los debates ${ }^{32}$, pero nunca estuvieron claras sus propuestas para cualquiera de los puntos fundamentales del proyecto. Algunos autores han apuntado a la presencia dentro del PSOE de unas tesis colectivistas ${ }^{33}$, inspiradas en los koljoses soviéticos, que se oponían al individualismo de los republicanos. En este sentido, es cierto que algunos diputados socialistas, como Gabriel Morón, criticaron los asentamientos individuales por ser «antisocialismo puro» ${ }^{34}$. Pero también lo que es que otros, como Juan Morán, terminaron aceptando la posibilidad de que los campesinos optaran por explotaciones individuales o colectivas según el tipo de cultivo $^{35}$, e incluso afirmaron, caso de Lucio Martínez Gil, que no era contradictorio favorecer la creación de pequeños propietarios con el ideario socialista $^{36}$. Es muy significativo que en los debates parlamentarios sobre la reforma agraria nunca intervinieran los ministros socialistas, ni cualquier otro de los líderes del partido ${ }^{37}$. Siempre se delegó en personajes de segunda fila, lo que revela bien la inexistencia de un criterio «oficial» o dominante respecto al problema de la agricultura, bien el temor a que la apuesta por una opción provocara una ruptura interna en el seno de la formación.

En realidad, las dudas socialistas ante el tema agrario solo pueden entenderse completamente si se contempla la posición del PSOE en el sistema de partidos. Por un lado, los socialistas nunca entendieron su papel dentro de la coalición gobernante del primer bienio más que como una alianza circunstancial con otros grupos republicanos. La visión de este rol determinó la orientación del PSOE, más reformista conforme se consolidaba su posición dentro del Gobierno, y viceversa. Solo si se observa la inestable relación de fuerzas en el Gobierno durante aquella etapa puede comprenderse que los socialistas se opusieran primero a los proyectos de la Comisión Técnica Agraria y después apoyaran fórmulas más limitadas. En este sentido, como apunta Malefakis, «la explicación de la postura contradictoria de los socialistas durante este período parece encontrarse en su temor a que los radicales venciesen en la pugna por conseguir el apoyo de los republicanos de izquierdas [...]. La continua inseguridad de los socialistas dentro del nuevo régimen les llevaba a descontar la posibilidad - tan temida por los propietarios- de que la "vaguedad" del proyecto de la Comisión Técnica llevase a una ocupación permanente de las tierras dado que los campesinos, una vez instalados, serían extraordinariamente difíciles de desalojar.

reforma agraria fueron ambiguas. Vid. El Socialista, 12 de julio de 1931. En el XIII Congreso ordinario del partido de octubre de 1932 tampoco se avanzó mucho, limitándose el PSOE a adoptar las propuestas del III Congreso que la FNTT (Federación Nacional de Trabajadores de la Tierra) habia celebrado dias antes. Vid. Actas del XIII Congreso del Partido Socialista Obrero Español, Madrid, Gráfica socialista, 1932, p. 126-135.

32 Por ejemplo, en la intervención de Lucio Martinez Gil, secretario general de la FNTT, DSCC, $\mathrm{n}^{\circ} 166$, 17 de mayo de 1932, p. 5.494-5.501.

33 Gerald Brenan, El laberinto español. Antecedentes sociales y politicos de la guerra civil, Paris, Ruedo ibérico, 1962, p. 185-186; Manuel Ramirez, Los grupos de presión, op. cit., p. 170-171.

34 DSCC, $\mathrm{n}^{\circ} 194,5$ de julio de 1932, p. 6.693.

35 DSCC, $\mathrm{n}^{\circ} 198,12$ de julio de 1932, p. 6.945-6.946.

36 DSCC, $\mathrm{n}^{\circ} 399,1$ de septiembre de 1933, p. 15.251-15.253.

37 Un hecho que llama mucho la atención si se atiende a la importancia social y económica de los Ministerios de Trabajo y Obras Públicas, que ocupaban Francisco Largo Caballero e Indalecio Prieto, respectivamente, y el papel de experto en cuestiones agrarias que desempeñaba Fernando de los Rios dentro del PSOE. Virgilio ZAPATERO, Fernando de los Rios: los problemas del socialismo democrático, Madrid, Edicusa, 1974, p. 100-103. 
En su lugar, el PSOE aceptó un programa mucho más moderado con la esperanza vana de que la menor ambigüedad de sus bases legales lo haría inalterable $\rangle^{38}$.

Efectivamente, conforme la alianza con los republicanos de izquierda se afianzó, el PSOE fue abandonando las posiciones maximalistas. Prueba de ello es la nula resistencia que opusieron a los proyectos de reforma presentados a lo largo de 1932 por Marcelino Domingo $^{39}$. Sin embargo, a medida que, durante 1933, la coalición republicanosocialista fue desintegrándose, el PSOE dejó de apoyar abiertamente el proyecto de Ley de Arrendamientos que se debatió en las Cortes e incluso manifestó su disconformidad con algunos de sus preceptos, anunciando además por boca de Lucio Martínez Gil que intentarían cambiarlos «cuando tengamos medios para ello» ${ }^{40}$. Ya en 1934, cuando pasaron a la oposición, los socialistas emprenderían la escalada de la pendiente revolucionaria ${ }^{41}$.

Por otra parte, la competencia de los socialistas con los anarquistas por ganarse a los campesinos condicionó la actitud de aquellos ante la cuestión agraria. Ya en el Congreso del PSOE de 1932 varios delegados apuntaron al peligro de un desbordamiento por la izquierda en caso de continuar apoyando la política reformista del Gobierno y demandaban un retorno a las «verdaderas posiciones de partido de clase y marxistas» para que «su programa no fuera arrebatado por otras organizaciones $»^{42}$. En las Cortes, Gabriel Morón se situó en una línea cercana, al defender los asentamientos colectivos frente a los individuales porque los últimos traerían consigo que «esos hombres que asentemos han de retirarse de las organizaciones obreras ${ }^{43}$. De forma parecida, la oposición en 1934 a la derogación de la Ley de Términos Municipales, que desembocó en la obstrucción de la minoría socialista al proyecto, estaría motivada en buena medida por el miedo a perder una herramienta legal que había permitido al PSOE y al sindicato UGT (Unión General de Trabajadores) competir en las zonas rurales con las organizaciones anarquistas ${ }^{44}$.

La permanencia de un partido como el PSOE en el bloque gubernamental que emprendió la reforma agraria en el primer bienio tuvo consecuencias inmediatas. Aunque es verdad que, al principio, los socialistas aceptaron e impulsaron la política reformista, cuando había que tomar decisiones trataban de salvaguardar su imagen obrerista y su vocación revolucionaria en el plano socioeconómico. Por ese motivo, introducían elementos en los proyectos, muchas veces puramente simbólicos, dirigidos a fidelizar a los campesinos y mantener la unidad entre sus bases. Sin embargo, muchos de esos elementos contradecían la naturaleza reformista de las medidas impulsadas por el Gobierno. Ya durante la elaboración de la Constitución, Alcalá-Zamora anunció el peligro de que las propuestas del PSOE en

38 Edward MaLefakis, Reforma agraria, op. cit., p. 213-214.

39 Según Manuel Azaña (Memorias politicas, op. cit, p. 322), cuando el Consejo de Ministros discutió estos proyectos a inicios de 1932, «Prieto, que "nunca creyó en la Reforma Agraria", dice que ahora empieza a ser viable. Largo también cede fácilmente. E1 que se resiste más es Ríos; tiene una especie de fanatismo de intelectual y disputa por entelequias. A veces, parece un niño consentido».

40 DSCC, $\mathrm{n}^{\circ} 391,18$ de agosto de 1933, p. 14.945.

41 Sobre este cascenson y para un análisis del dilema reforma/revolución, vid. Santos Juliá, La izquierda del PSOE (1935-1936), Madrid, Siglo XXI, 1977; y Andrés DE BLAs, El socialismo radical en la II República, Madrid, Túcar, 1978.

42 Palabras de Luis JiméNEZ de Asúa en Actas del XIII Congreso, op. cit., p. 404. Vid. también sobre este tema Manuel Tuñón de LaRa, Tres claves de la Segunda República. La cuestión agraria, los aparatos del Estado, Frente Popular, Madrid, Alianza, 1985, p. 87 y ss.

43 DSCC, $\mathrm{n}^{\circ} 194,5$ de julio de 1932, p. 6.693-6.694.

44 Cfr. la defensa del voto particular de Anastasio de Gracia -que sería elegido presidente de UGT ese mismo año- contra el dictamen de la Comisión de Trabajo, en $D S C, \mathrm{n}^{\circ}$ 29, 26 de enero de 1934, p. 718-720. 
torno a la propiedad privada acarrearan una disminución de la riqueza, sin conseguir nada más, ni siquiera desde un punto de vista socialista ${ }^{45}$. Después, cuando se redactó la Ley de Reforma Agraria de 1932, después de hacer concesiones en sus pilares maestros, los socialistas se encastillaron en intransigencias y radicalismos sobre aspectos secundarios. La consecuencia fue extender sus efectos de aplicación a pequeñas y medianas explotaciones, lo que incitó la enemiga de sus propietarios hacia el régimen, aumentó innecesariamente los gastos del erario público y dispersó los esfuerzos del Estado, que deberian haberse concentrado sobre los grandes terratenientes y sus fincas ${ }^{46}$.

Lo peor fue que la actitud socialista alimentó que los partidos situados en la oposición al Gobierno cimentasen su desacuerdo con los proyectos en las tesis socialistas sobre la propiedad, como si en realidad aquéllos estuvieran inspirados por éstas. Y así, los debates sobre la reforma agraria se plantearon como una lucha entre colectivismo e individualismo. En unlado de la contienda se situaron los partidos republicanos de oposición, que denunciaron el «sometimiento» de la izquierda republicana en el Gobierno a los planteamientos del PSOE como el escollo que obstaculizaba la unidad entre republicanos y que justificaba su desacuerdo con los proyectos. El radical Rafael Guerra del Río representaría esta postura al afirmar: «Ya empezamos a no hacernos la ilusión de que volvamos a encontrar los votos republicanos [...]; por eso decimos que si una vez más volviera a triunfar aquí el criterio exclusivamente socialista, si esa mayoría se sometiera una vez más al criterio socialista, tened en cuenta que a nosotros nos queda un derecho: podréis gobernar con esa mayoría aquí. Con nuestros votos, en este sentido, no gobernaréis un día solo ${ }^{47}$. Junto a éstos, las derechas negaron incluso la posibilidad de una alternativa reformista, manifestando, como hiciera el diputado agrario Cándido Casanueva, que su único enemigo era el socialismo: «Soy castellano viejo y [...] al pan, pan, y al vino, vino. La Ley de Arrendamientos [...] la han impuesto ésos, los socialistas [...]. En la Ley de Arrendamientos a mí me han puesto la ceniza en la frente los socialistas y los demás de la mayoría. Los radicales han contribuido a impedir que me la pongan por completo ${ }^{48}$.

Las contradicciones del PSOE contagiaron pronto a todo el Gobiemo, cuyo «moton» parlamentario no era otro el que le proporcionaba la minoría socialista ${ }^{49}$. Como los lideres socialistas, las principales figuras de la mayoria gubernamental se abstuvieron de intervenir en el Parlamento, no por falta de interés, sino por carecer de unos criterios definidos al respecto. Y esta inhibición fue la causa del éxito de la obstrucción practicada en la Cámara por la minoría agraria ${ }^{50}$. Sobre todo con la Ley de Arrendamientos Rústicos de 1933, el debate fue un diálogo entre los miembros de la Comisión y los diputados agrarios, sin participación de los ministros y los primeros espadas de los principales partidos. El ministro

45 DSCC, $\mathrm{n}^{\circ} 50,6$ de octubre de $1931, \mathrm{p}, 1.432$.

46 Cfr., en este sentido, las extensas consideraciones de Edward MalefaKis, Reforma agraria, op. cit., p. 243-277; y las más breves de Pascual CARrión, La reforma agraria de la Segunda República, op. cit., p. 123-126. Un análisis juridico del contenido de la Ley de Reforma Agraria de 1932 en Gregorio PECESBarba del. Brio, La Ley de Reforma Agraria. Precedentes y estado actual del problema en Europa, Madrid, Imprenta José Murillo, 1932.

47 DSCC, $\mathrm{n}^{\circ} 385,9$ de agosto de 1933, p. 14.713.

48 DSCC, $\mathrm{n}^{\circ} 399,1$ de septiembre de 1933, p. 15.253.

49 De hecho, como ha estudiado Edward MaLEFAKIs (Reforma agraria, op. cit., p. 305-381), los enfrentamientos en el seno de la mayoria gubernamental, que desembocaron en la ruptura entre republicanos y socialistas en 1933 , tuvieron como causa principal las diferencias en la politica social y económica.

50 Especialmente enconada durante los debates del proyecto de Ley de Arrendamientos Rústicos, a cuyo artículo $1^{\circ}$ presentaron 205 enmiendas. 
Marcelino Domingo solo hizo uso de la palabra en una ocasión, para trazar las líneas generales de la Ley de Reforma Agraria de $1932^{51}$, y ni siquiera eso cuando se discutió la Ley de Arrendamientos el año siguiente. Azaña intervendría en tres ocasiones, pero con objetivos más políticos que sociales o económicos: dos veces para obtener de las Cortes la expropiación de las tierras de los implicados en el golpe de Estado de Sanjurjo y de los Grandes de España, como «determinación de carácter político» que diera «una satisfacción a la conciencia republicana española $\rangle^{52}$; y una tercera, en el verano de 1933, para dar un toque de atención a los diputados de la mayoría, que con su repetida ausencia del hemiciclo durante los debates de la Ley de Arrendamientos ponían en peligro «la continuidad de la política que nosotros representamos $\rangle^{53}$.

La fragmentación dentro de la mayoría gubernamental se manifestó en lo que Tamames llama «falta de una línea básica» ${ }^{54}$, es decir, coherencia a la hora de poner en práctica la Ley de Reforma Agraria de 1932. Frecuentemente se adujo que la reforma era producto de una serie de pactos en virtud de los cuales se habían aparcado los principios en aras del consenso. Y, en efecto, algunos expertos de la época ya apuntaron, no sin alarma, que tales transacciones había tenido como resultado contradicciones importantes. El historiador Juan Díaz del Moral ${ }^{55}$, adscrito a la Agrupación al Servicio de la República, trató de advertir a los diputados de que «el proyecto ministerial y el dictamen consiguiente adolecen [...] del defecto de que son la resultante de [...] una conveniencia entre principios que allá, en su fondo, en su raíz más profunda, son internamente contradictorios. De modo que en su desarrollo futuro tal vez ocasionen complicaciones y dificultades ${ }^{56}$.

Los problemas más graves se derivaron de la falta de unos límites espaciales de aplicación de la reforma. La política social y económica progresista que se intentó implantar en el primer bienio se encontró, como señalara Beiras, con la diversidad de condiciones existentes en las diferentes regiones españolas ${ }^{57}$. En este sentido, los socialistas concebían la reforma agraria como una herramienta para paliar los agudos problemas sociales de las áreas latifundistas meridionales ${ }^{58}$, lo que provocaría el choque de los grandes propietarios con el campesinado reunido en torno a los sindicatos y organizaciones proletarias. Por el contrario, la izquierda republicana aspiraba a una reforma agraria centrada en los intereses de los pequeños propietarios y arrendatarios de Castilla la Vieja, Levante y la cornisa cantábrica. Hubieran sido necesarias, por tanto, dos «reformas agrarias» diferenciadas, adaptadas a la situación del minifundio y el latifundio, respectivamente, no una sola extendida a todo el territorio nacional. Se cayó así en lo que Sánchez-Román calificaría de «error gravísimo» ${ }^{59}$ :

$51 D S C C, \mathrm{n}^{\circ} 183,15$ de junio de 1932, p. 6.214-6.221.

$52 D S C C, \mathrm{n}^{\circ} 220,18$ de agosto de 1932, p. 8.045-8.047; y n ${ }^{\circ} 232,8$ de septiembre de 1932, p. 8.674-8.676.

53 DSCC, $\mathrm{n}^{\circ} 395,25$ de agosto de 1933, p. 15.088.

54 Ramón TAmames, Estructura económica de España, op. cit., vol. I, p. 71.

55 Poco antes del advenimiento de la República había publicado Historia de las agitaciones campesinas andaluzas, Madrid, Revista de Derecho Privado, 1929; libro considerado por Manuel TuÑón DE LARA («Un adelantado de la historia social: Juan Díaz del Moral», en El País, 13 de abril de 1980) como "cimiento insoslayable» de la historia social española, en el que estudiaba las organizaciones obreras y patronales de Córdoba durante el «trienio bolchevista» (1918-1920).

56 DSCC, $\mathrm{n}^{\circ} 162,10$ de mayo de 1932, p. 5.481.

57 Xosé María BerRas, «La economía española durante la Segunda República», en Manuel Ramírez et al., Estudios sobre la II República, op. cit., p. 157-158.

58 La base segunda del proyecto elaborado por la Comisión Técnica Agraria en 1931 limitaba el alcance de aplicación de la reforma a las provincias de Andalucía y Extremadura, más Ciudad Real y Toledo.

$59 D S C C, \mathrm{n}^{\circ} 175,1$ de junio de 1932, p. 5.951. 
aplicar soluciones uniformes -las previstas para las condiciones del sur peninsular- a problemas distintos.

La consecuencia de ello fue la dispersión de los mermados recursos financieros y humanos del Estado dedicados a la reforma agraria, además de la insatisfactoria respuesta a las demandas específicas de los arrendatarios y pequeños propietarios ${ }^{60}$, quienes, como tempranamente notara Pascual Carrión, pronto se encontraron entre sus enemigos ${ }^{61}$. Algunos diputados trataron de hacer ver la conveniencia de modular la reforma a las distintas necesidades regionales y evitar el uniformismo ${ }^{62}$. Al final, todo fue en vano, con lo que bien pudo el diputado galleguista Alfonso Rodríguez Castelao escribir: «¿Puede acaso el Estado centralista [...] preocuparse de otra cosa que no sea el transformar la estructura de sus latifundios, quitándole la tierra a quien no la trabaja, para constituir por fin la clase agraria que necesita? No; el Estado actual no tiene tiempo para ocuparse del problema minifundista de Galicia, aunque éste aparezca teñido de terribles injusticias y su desorden tenga fácil solución con solo aceptar la necesidad de una reforma múltiple. Pero como Galicia no es una estepa y sus problemas son minoritarios, quedará siempre excluida del "interés nacional" en tanto la ley sea única»" ${ }^{63}$.

Las incoherencias y fisuras del reformismo agrario no fueron exclusivas de los partidos de la mayoría, sino que se extendieron por todo el arco parlamentario, afectando también a la oposición. El caso del PRR es el más significativo ${ }^{64}$. Es cierto que los radicales carecían de una postura consistente al respecto desde 1931, pero conforme hubieron de desempeñar el papel de principal partido de la oposición y alternativa a la coalición republicano-socialista gobernante, esta carencia se hizo todavía más patente. En el esfuerzo por clarificar su programa socio-económico durante este primer bienio se encontrarán la heterogeneidad y vacilaciones que caracterizarían al PRR en los años siguientes, ya en el poder ${ }^{65}$.

Durante la discusión parlamentaria de la Ley de Reforma Agraria, los radicales se dividieron en dos corrientes. Unos se dedicaron a romper la unidad entre republicanos de izquierdas y socialistas, tratando de atraer a los primeros a una solución centrista,

60 Según Gerald BRENAN (El laberinto español, op. cit., p. 187): «No se hizo nada para remediar a las innumerables familias del norte que tenían pocas tierras ni para convertir la variable y usualmente excesiva renta de Castilla en un censo fijo o bail héréditaire. Podemos decir aquí que los partidos republicanos perdieron una gran oportunidad, no solamente de remediar los abusos escandalosos que se producían en el campo, sino también de ganar aliados que hubieran fortalecido considerablemente el régimen».

61 Pascual CARrión, La reforma agraria de la Segunda República, op. cit., p. 124.

62 En este sentido, vid., por ejemplo, las intervenciones de Ramón Otero Pedrayo (Partido Nazonalista Repubricán de Ourense), DSCC, ${ }^{\circ} 167,18$ de mayo de 1932, p. 5.654-5.659; de Leandro Pita Romero (galleguista independiente), DSCC, $\mathrm{n}^{\circ} 179,8$ de junio de 1932, p. 6.078-6.084; de Rafael Aizpún Santafé (tradicionalista navarro), DSCC, $\mathrm{n}^{\circ}$ 191, 29 de junio de 1932, p. 6.554-6.557; y de Andrés Orozco Batista (canario del PRR), DSCC, $\mathrm{n}^{\circ} 195,6$ de julio de 1932, p. 6.778-6.783.

63 Alfonso Rodriguez Castelao, Sempre en Galiza (versión en castellano). Vol. 2: Obra Completa, Madrid, Akal, 1977, p. 18.

64 Pero no el único. Ya Richard Alan Hodgson Robinson (The Origins of Franco's Spain: The Right, The Republic \& Revolution, 1931-1936, Pittsburgh, Pittsburgh University Press, 1970, p. 88-89) puso de manifiesto las fisuras internas dentro de otras minorías parlamentarias de oposición, incluso en algunas tan aparentemente compactas ante el problema como la agraria.

65 Los problemas para definir al PRR como una vía homogénea de agregación de intereses fueron señaladas por Manuel Ramírez, "La agregación de intereses», op. cit., p. 35-36. Sobre la reforma agraria y los radicales, vid. los libros de Octavio Ruiz-Manjón, El Partido Republicano Radical, 1908-1936, Madrid, Tebas, 1976, p. 292-302, y La evolución programática del Partido Republicano Radical, Madrid, Universidad Complutense, 1980, p. 433-435; y el más reciente de Nigel Townson, La República que no pudo ser. La politica de centro en España (1931-1936), Madrid, Taurus, 2012, p. 167-178. 
«de amplia coincidencia republicana» ${ }^{66}$. Otros, en absoluto convencidos del éxito de la operación de convergencia, se alinearon con los partidos de derecha, defensores de los intereses afectados por las reformas. Ambos grupos terminaron molestándose mutuamente, de manera que el PRR quedó incapacitado para presentar cualquier proyecto coherente que se opusiera a la reforma concebida por el Gobierno ${ }^{67}$. Una incapacidad reconocida por Ricardo Samper, encargado de manifestar la postura del radicalismo ante la Ley de Reforma Agraria de 1932: «Parece difícil, a primera vista, interpretar la voluntad colectiva de la minoría radical, porque vosotros, como yo, habréis advertido que hay en ella variedad de matices, que comparten su disciplina elementos de ideas francamente avanzadas, mientras que hay otros de tono prudente y comedido ${ }^{68}$. Las propuestas derivadas de esta incoherencia no podían ser más sorprendentes: «Ya que se impone al propietario el sacrificio de la expropiación, hay que hacerlo, al menos, con un tono amable, con buen talante, si es posible hasta con cordialidad ${ }^{69}$.

Dada la falta de un criterio claro, al PRR solo le cupo aprovechar los debates parlamentarios para desgastar al Gobierno, dejando a un lado el contenido de la reforma agraria, hasta el punto que Andrés Orozco llegó a decir que la actitud de su partido «se amoldaría» al trato que la mayoría le dispensara ${ }^{70}$. Esa es la razón por la cual los diputados radicales terminaron convirtiendo los debates agrarios en discusiones sobre la política general, haciendo abstracción de las medidas concretas. Y es que, como planteaba Rafael Guerra del Río, «no se trata de la ley, sino de algo más fundamental [...]: la falta de asistencia de la mayoría a la obra del Gobierno la interpreta éste como lo que democráticamente, parlamentariamente, tiene que significar: como una falta de confianza y de ayuda que el Gobierno necesita en cada momento ${ }^{71}$.

\section{El bienio radical-cedista y la actitud de la CEDA}

Si durante el primer bienio el partido más dividido en torno a la cuestión agraria fue el PSOE, en la segunda Legislatura de la República (1933-1935) lo sería la CEDA, formación más importante dentro de la mayoría parlamentaria. Su ala izquierda no consideraba necesario revocar las reformas realizadas en la etapa anterior, si bien pretendía retocarlas para introducir algunos elementos propios de la doctrina social católica, como el fomento de los pequeños patrimonios y la defensa de las propiedades familiares, en lo que cabía esperar el apoyo del PRR, de los republicanos conservadores e incluso de los republicanos de izquierda ahora en la oposición. Frente a ellos se situaba el sector motejado gráficamente por Giménez Fernández como «los conservaduros» ${ }^{72}$, partidario de llevar el campo a la

66 Vid., por ejemplo, las intervenciones de Alejandro Lerroux, durante un debate de política general, $D S C C, \mathrm{n}^{\circ} 203,20$ de julio de 1932, p. 7.194-7.202; de Eloy Vaquero, DSCC, $\mathrm{n}^{\circ} 199,13$ de julio de 1932, p. 6.987-6.991; y de José María Álvarez-Mendizábal, DSCC, $\mathrm{n}^{\circ} 226,30$ de agosto de 1932, p. 8.279-8.283.

67 Resulta muy elocuente que el voto particular presentado por Diego Hidalgo, diputado del PRR, al proyecto de Ley de Reforma Agraria, tuviera que ser defendido sin el apoyo explícito de sus compañeros de escaño, aunque, según él, «la minoría radical estuviera identificada con dicha propuesta en términos generales»,. DSCC, $\mathrm{n}^{\circ} 163,11$ de mayo de 1932 , p. 5.515 .

68 DSCC, $\mathrm{n}^{\circ} 170,24$ mayo de 1932, p. 5.746.

69 Ibidem, p. 5.750.

70 DSCC, $\mathrm{n}^{\circ} 195,6$ de julio de 1932, p. 6.784.

71 DSCC, $\mathrm{n}^{\circ} 395,25$ de agosto de 1933, p. 15.091.

72 Éstos le correspondían llamándole «bolchevique blanco» y «marxista camuflado». (Hugh THOMAS, La Guerra Civil española, 1936-1939, vol. I, Barcelona, Grijalbo, 1985, p. 171). 
situación de 1931, aunque incrementando las medidas de protección sobre los productos agrarios. Este grupo contaba con el respaldo del Partido Agrario Español (PAE), de la Lliga Catalana y, fuera de la coalición gubernamental, de los monárquicos.

La fragmentación de la CEDA comenzó a hacerse patente cuando el ministro de Agricultura, Cirilo del Río, presentó ante las Cortes, en enero de 1934, su primer proyecto sobre intensificación de cultivos en Extremadura ${ }^{73}$. Las intervenciones de los diputados contrarios -Mateo Azpeitia, Cándido Casanueva o Adolfo Rodríguez Jurado-y favorables al proyecto -Manuel Giménez Fernández- marcaron el inicio de las divisiones internas ${ }^{74}$. Cuando hubo de votarse el proyecto, muchos parlamentarios cedistas rompieron la disciplina de voto ${ }^{75}$. Al final, aunque la ley salió adelante, los «conservaduros» de la CEDA obstruyeron sistemáticamente todas las iniciativas que Cirilo del Río llevó después a la Comisión de Agricultura de las Cortes ${ }^{76}$.

La llegada de Giménez Fernández al Ministerio de Agricultura exacerbó las contradicciones existentes en el seno de la mayoría parlamentaria y de la CEDA ${ }^{77}$. Sus proyectos de reforma colocaron al partido católico en la disyuntiva de decantarse hacia una vertiente moderada democristiana o hacia otra abiertamente conservadora. Dado que la CEDA era a la vez una cosa y la otra, o al menos bajo sus siglas había personajes adscritos a ambas sensibilidades, para evitar un probable cisma en su interior, al final se optó por postergar algunos de estos proyectos, alterar el sentido primigenio de otros e impedir el debate parlamentario de los demás, todo ello sin perder la primera ocasión que se presentara para provocar la destitución del titular de la cartera. Un cese que se revelaría trascendental para mantener la unidad del partido y de la coalición gobernante ${ }^{78}$.

En un principio, parecía que las reformas de Manuel Giménez Fernández tenían más opciones de prosperar que las de Cirilo del Río. Y ello porque en aquellos meses se ausentaron de las sesiones algunos diputados de la izquierda, como protesta por la represión desencadenada tras los sucesos de octubre de 1934, tras lo que cabía esperar una menor oposición. Además, al ser el nuevo ministro del ramo perteneciente a la CEDA, las posibles

73 Sergio RIESCO, "La intensificación de los cultivos durante la reforma agraria de la Segunda República: ¿alternativa o complemento?», en Ricardo Robledo y Santiago López GARcía (coords.), ¿Interés particular, bienestar público? Grandes patrimonios y reformas agrarias, Zaragoza, Universidad de Zaragoza, 2007, p. 363-388.

$74 D S C, \mathrm{n}^{\circ} 31-37,31$ de enero - 9 de febrero de 1934, p. 800-1.016.

75 En la última votación nominal sobre la Ley de Yunteros (DSC, $\mathrm{n}^{\circ} 37,9$ de febrero de 1934, p. 1.0161.018), algunos diputados de la CEDA se situaron al lado del PSOE, Izquierda Republicana, PRR, republicanos conservadores y liberal-demócratas, mientras que otros lo hicieron junto al PAE y los monárquicos.

76 Bloquearon especialmente el proyecto de Ley de Arrendamientos. Aunque Edward MaLEFAKis (Reforma agraria, op. cit., p. 347) afirma que, tras su paso por la Comisión, «los rasgos esenciales del proyecto ministerial quedaron intactos» y las modificaciones fueron «de poca importancia», lo cierto es que el texto quedó tan irreconocible que el propio Cirilo del Río lo retiró antes de que se discutiera en el Pleno, como reconocieron el propio ministro y el presidente de la Comisión, Cándido Casanueva, en un debate que mantuvieron tiempo después y que puede consultarse en DSC, $\mathrm{n}^{\circ} 133$ y 134,5 y 6 de diciembre de 1934 , p. $5.263-5.268$ y $5.294-5.299$

77 Un resumen del pensamiento de Giménez Fernández y, en concreto, de la política agraria que trató de implementar, en Javier Tuselt, Historia de la Democracia Cristiana en España, vol. I, Madrid, Edicusa, 1974, p. 282-312.

78 José María GL-Robles (No fue posible la paz, Barcelona, Planeta, 1968, p. 187) reconocería años más tarde que no se «atrevió» a mantener a Giménez Fernández en el Gobierno por el «riesgo que ello supondría para la estabilidad del bloque gubernamental» y dado que, dentro de la CEDA, «el grupo de los descontentos arreciaba en la ofensiva». 
resistencias que pudiera suscitar el desarrollo del programa reformista entre los diputados del partido católico debían ser frenadas por los mecanismos de disciplina interna que regían en la llamada «minoría popular agraria».

En este sentido, Giménez Fernández afirmó insistentemente en sus intervenciones parlamentarias la unidad del grupo parlamentario cedista en torno a sus proyectos, así como la coincidencia entre éstos y los planteamientos de su líder, José María Gil-Robles: «Esta minoría [...] tiene también, y tengo yo [...], el concepto claro y fundamental de la voluntad unitaria, el criterio del jefe [...]. No cuando existan discrepancias, sino cuando dejen de existir coincidencias entre el criterio del jefe y el mío, no seguiré un minuto más en el banco azul. Por consiguiente, mientras esté aquí no se puede especular con que hay diferencias de criterio entre la minoría a que pertenezco y yo» ${ }^{79}$. En una línea similar se expresaría, años después, Gil-Robles en sus memorias, al recalcar la «ejemplar» disciplina de sus diputados: «No me cansaré de proclamar la abnegada disciplina de la inmensa mayoría de los miembros del grupo parlamentario. Obligados a secundar, por patriotismo, una política que pugnaba muchas veces con sentimientos muy arraigados; $[\ldots]$ los diputados de la CEDA supieron mantenerse unidos y confiados, acatando gustosos una disciplina que les imponía grandes sacrificios y anulando generosamente poderosas individualidades en el anónimo de la labor colectiva»s ${ }^{80}$.

Es verdad que, ante las críticas lanzadas por agrarios y monárquicos contra Giménez Fernández con motivo de la discusión de la Ley de Yunteros $^{81}$, los diputados cedistas estuvieron, en líneas generales, apoyando al ministro, si bien en las votaciones de algunos artículos se produjeron grietas y las abstenciones finales impidieron que el proyecto se aprobara con rapidez, al exigir los monárquicos quórum en la votación definitiva ${ }^{82}$. Y también lo es que, cuando se presentó un nuevo proyecto de Ley de Arrendamientos, casi idéntico al que no había podido sacar adelante Cirilo del Río y muy similar al de Marcelino Domingo ${ }^{83}$, éste pudo discutirse en las Cortes gracias a un voto particular elaborado por el propio ministro y sostenido por el presidente de la Comisión de Agricultura, Cándido Casanueva, justo quien se había mostrado más tenazmente en contra de las anteriores reformas ${ }^{84}$.

Sin embargo, a partir de ese momento se dispararon las tensiones dentro de la CEDA a cuenta del problema agrario, como el propio Gil-Robles reconocería, pese a las protestas manifestadas sobre la unidad «abnegada» de su grupo ${ }^{85}$. En primer lugar, los diputados católicos dejaron desasistido a su ministro en la defensa de los proyectos ${ }^{86}$. Y otro tanto hicieron el presidente del Gobierno, Lerroux, y el jefe de la CEDA, Gil-Robles, aduciendo

$79 D S C, \mathrm{n}^{\circ} 137,12$ de diciembre de 1934, p. 5.420.

80 José María GLl-Robles, No fue posible la paz, op. cit., p. 182-183.

81 Vid., sobre la problemática que condujo al planteamiento de esta norma, Sergio RIESCO, «La cuestión yuntera en Extremadura durante la II República», en Historia Social, n 65 , 2009, p. 41-69.

82 Para que el proyecto de Ley de Yunteros fuera definitivamente aprobado hubo que esperar a que entrara en vigor el Reglamento definitivo de las Cortes, cuyo art. 91 rebajaba considerablemente, respecto al provisional de 1931, el número de diputados necesarios para que una ley saliera adelante. DSC, $\mathrm{n}^{\circ} 131$ y $142-143,30$ de noviembre y 19 y 20 de diciembre de 1934, p. 5.174-5.186, 5.620-5624 y 5.661-5.663. Edward Malefakis (Reforma agraria, op. cit., p. 402) calificó de "repugnante» esta pieza de filibusterismo parlamentario, habida cuenta de que, ante lo avanzado de la época de siembra, los yunteros se vieron muy perjudicados.

83 Como reconoció el propio Giménez Fernández en DSC, $\mathrm{n}^{\circ} 137,12$ de diciembre de 1934, p. 5.408.

$84 D S C, \mathrm{n}^{\circ} 133,5$ de diciembre de 1934, p. 5.263-5.268.

85 José María GLl-Robles, No fue posible la paz, op. cit., p. 177-182.

86 Giménez Fernández intervino en veintiuna de las sesiones dedicadas a discutir el proyecto de Ley de Arrendamientos, y más de una vez en alguna ocasión. 
el peligro de que, si «tomaban postura», la unidad de la coalición gubernamental y del propio partido mayoritario se vinieran abajo ${ }^{87}$. También por entonces empezaron a reproducirse las intervenciones de diputados de la CEDA que estaban abiertamente en contra de las reformas de Giménez Fernández y las votaciones en que la minoría popular agraria apareció completamente dividida ${ }^{88}$. Además, serían los parlamentarios cedistas los principales responsables de que los proyectos del ministro que seguían en la Comisión de Agricultura quedaran alli bloqueados y no pasaran a debate en el Pleno.

La lógica consecuencia de todo esto fue el fracaso del nuevo programa reformista llamado a solucionar el sempiterno problema agrario. Las contradicciones y luchas internas de la CEDA, similares, aunque de signo contrario, a las que había sufrido el PSOE durante la Legislatura Constituyente, hicieron imposible la puesta en marcha de las medidas propuestas. La Ley de Yunteros sufrió, como hemos visto, un retraso en su aprobación que afectó negativamente a sus teóricos beneficiarios. La Ley de Arrendamientos quedó irreconocible en relación al proyecto ministerial, de tal manera que lo que debía ser una herramienta de defensa al servicio de los arrendatarios se convirtió en un ariete empleado por los grandes propietarios para acelerar los desahucios ${ }^{89}$. Un texto que regulaba el aumento de las zonas de pequeño cultivo fue frenado primero en la Comisión de Agricultura y luego en el Pleno, después de que varios diputados de la CEDA iniciaran una ofensiva contra él ${ }^{90}$. Otro proyecto, capital para Giménez Fernández, como era el de acceso de los colonos a la propiedad, después de haberse desgajado del de Arrendamientos -donde se encontraba al principio incluido- ni siquiera llegó a discutirse como consecuencia del obstruccionismo de la Comisión ${ }^{91}$. Por ultimo, el nuevo proyecto de Reforma Agraria ni siquiera llegaría a ser presentado ante las Cortes ${ }^{92}$. Con este abultado bagaje de derrotas, Giménez Fernández abandonó el Ministerio en abril de 1935.

Después de su cese, la política agraria entró en un período, más que «rectificador» como a veces se ha tildado eufemísticamente-, contrarreformista. El centro de gravedad de la coalición gubernamental se había deslizado hacia la derecha y las responsabilidades del Departamento de Agricultura fueron encomendadas a figuras del PAE ${ }^{93}$. La estrategia de retraimiento del PSOE hizo que la oposición parlamentaria a las medidas propuestas,

87 El apoyo de José María Gll-Robles (No fue posible la paz, op. cit., p. 175.) se limitaba a, colocándose (cen alguno de los pasillos de acceso al salón de sesiones» y "a cubierto de miradas indiscretas», "animar con el gesto a Giménez Fernández en su lucha generosa o moderar en lo posible sus naturales reacciones violentas»y.

88 Entre los diputados de la CEDA que intervinieron en las Cortes para oponerse a Giménez Fernández, casi todos ellos grandes terratenientes, destacamos a Adolfo Rodríguez Jurado (presidente de la Asociación de Propietarios Rústicos de España), Cándido Casanueva, Mateo Azpeitia, Jaime Oriol de la Puerta, José María Fernández-Ladreda, Luis Alarcón de la Lastra, José Finat y Escrivá de Romaní (conde de Mayalde) y Mariano de la Hoz.

89 Hasta en el diario católico El Debate, 14 de febrero de 1935, se denunció «toda la labor desfiguradora de la ley que han hecho los dominadores de la Comisión de Agricultura».

90 Javier Tusell, Historia de la Democracia Cristiana, op. cit., vol. I, p. 299-302. Vid. el proyecto de ley en $D S C$, ap. $15^{\circ}$ al n ${ }^{\circ} 146,23$ de enero de 1935. Fue rechazado primero por la Comisión de Agricultura y posteriormente por el Pleno de la Cámara. DSC, $\mathrm{n}^{\circ} 166$ y 172, 27 de febrero y 15 de marzo de 1935 , p. 6.674-6.680 y $6.961-6.973$.

91 El proyecto de ley en DSC, ap. $6^{\circ}$ al n 132,4 de diciembre de 1934. Las maniobras de la Comisión de Agricultura en José María Gil-Robles, No fue posible la paz, op. cit., p. 184-185.

92 Ibidem, p. 185-186. Giménez Fernández concedió una entrevista a El Debate, 1 de enero de 1935, en el que exponía las líneas maestras de la reforma agraria que proyectaba.

93 Juan José Benayas (abril-mayo), Nicasio Velayos (mayo-septiembre) y José Martínez de Velasco (septiembre-octubre) ocuparian sucesivamente la cartera de Agricultura durante 1935. Una prueba 
reducida a los partidos republicanos de izquierda, quedara muy mermada. El PRR, en pleno proceso de descomposición tras la salida de Diego Martínez Barrio y sus fieles ${ }^{94}$, apenas pudo corregir la derechización dentro de la mayoría. Finalmente, la experiencia de Giménez Fernández había demostrado el corto alcance del reformismo auspiciado por la CEDA: haciendo abstracción de la cuestión religiosa, el ya ex ministro tenía más apoyos en los partidos situados a la izquierda del hemiciclo que en los de la derecha, que le profesaban una añadida antipatía por su republicanismo sin reservas ${ }^{95}$. Como ha escrito Montero Gibert, «la rama demócrata-cristiana de la CEDA [...] vióse anegada por el tronco cedista, cuya tendencia dominante y contrarrevolucionaria dio tono y pautas diferentes al partido como un todo» ${ }^{96}$.

La etapa contrarreformista quedaría consagrada en el plano legislativo con el nuevo proyecto de Ley de Reforma Agraria, que vino a congelar el aprobado en la etapa de Marcelino Domingo, presentado a las Cortes por el nuevo ministro Nicasio Velayos y aprobado a toda velocidad, en solo cinco sesiones ${ }^{97}$. El propio Velayos aclararía que la ley de 1932 había supuesto «que el campo y la tierra no significan nada de lo que han significado siempre y queremos nosotros que signifiquen»; había, pues, que regresar a la situación anterior mediante una nueva normativa «que lleve la paz a los espíritus y permita que puedan deducirse las consecuencias y obtenerse los provechos que han de derivarse de que en el campo haya paz y orden, de que la tierra se explote de una manera racional y tranquilas ${ }^{98}$. Con este objetivo se introdujeron modificaciones sustanciales en el proyecto que reforzaron de tal forma su carácter reaccionario que el ex ministro Cirilo del Río pudo decir lo que sigue: «En el Ministerio habrá cola de propietarios decididos a pedir por favor que incluyan sus fincas en la Reforma Agraria, porque os habéis dado tal maña, que lo que era un sacrificio y un recorte para la propiedad privada extensa, lo habéis convertido en un gran beneficio para ella $)^{99}$.

Finalmente, el proyecto sería aprobado sin dificultades por una amplia mayoría en las Cortes. Además de los agrarios, los monárquicos de Renovación Española dieron su conformidad por boca de Honorio Maura ${ }^{100}$, la CEDA por la de Adolfo Rodríguez Jurado ${ }^{101}$ y la Lliga por la de Manuel Florensa ${ }^{102}$. La minoría de ERC (Esquerra Republicana de Catalunya) se abstuvo y su portavoz, Melchor Marial, pidió que se respetara la competencia exclusiva del Parlamento de Cataluña sobre la materia en los límites de su demarcación ${ }^{103}$. De manera

elocuente de la vía muerta en que entró la reforma agraria a lo largo de aquel año la da el hecho de que en septiembre de 1935 se refundiera Agricultura con Industria y Comereio en un solo Ministerio.

94 Sobre esta escisión, que en 1934 daría lugar al Partido Radical Demócrata y, tras la fusión con el Partido Republicano Radical Socialista, a Unión Republicana, vid. Octavio Rutz-Manjón, El Partido Republicano Radical, op. cit., p. 413-454.

95 José María G⿺-Robles, No fue posible la paz, op. cit., p. 174. Para indignación de las derechas, Giménez Fernández reiteraría insistentemente, en las Cortes de 1936, su «amor a la República». Vid. DSC, n³1, 21 de mayo de 1936, p. 794.

96 José Ramón Montero Gibert, «La CEDA; el partido contrarrevolucionario hegemónico de la Segunda República», en Manuel Ramírez et al., Estudios sobre la II República, op. cit., p. 121. Vid. también, de este mismo autor, su trabajo La CEDA. El catolicismo social y politico de la II República, 2 vols., Madrid, Editorial Revista del Trabajo, 1977.

97 Su contenido ha sido analizado por Edward MALEFAKIS, Reforma agraria, op. cit., p. 411-415.

$98 D S C, \mathrm{n}^{\circ} 229,24$ de julio de 1935, p. 9.401 .

$99 D S C, \mathrm{n}^{\circ} 228,23$ de julio de 1935 , p. 9.358 .

100 DSC, $\mathrm{n}^{\circ} 227,20$ de julio de 1935 , p. 9.320 .

101 Ibidem, p. 9.320-9.322.

$102 D S C, n^{\circ} 229,24$ de julio de 1935, p. 9.396-9.400.

103 DSC, $\mathrm{n}^{\circ} 230,25$ de julio de 1935 , p. 9.442-9.443. 
parecida, Manuel de Irujo, en nombre del Partido Nacionalista Vasco, se limitó a defender las particularidades agrarias de su región ${ }^{104}$. Los diputados de IR (Izquierda Republicana) abandonaron el salón de sesiones ${ }^{105}$. Así pues, la Ley de Reforma de la Reforma Agraria tuvo por toda oposición a UR (Unión Republicana), cuyo punto de vista fijó Fulgencio Díez Pastor $^{106}$, y algunos diputados aislados de distinto signo, como el ex ministro progresista Cirilo del Río o el flamante líder falangista José Antonio Primo de Rivera ${ }^{107}$.

La minoría radical y socialcristiana que permanecía dentro de la coalición gubernamental consiguió arrancar algunas mejoras, pero no modificar el carácter reaccionario de la ley. Así, Giménez Fernández logró lo que se le había resistido en su etapa como ministro: la posibilidad de que los arrendatarios accedieran a la propiedad. Y José María ÁlvarezMendizábal vio como se le admitía una enmienda que contemplaba la facultad del Estado para expropiar fincas por razones de «utilidad social». Esta última careció de virtualidad mientras los agrarios estuvieron al frente del Ministerio de Agricultura, pero, como veremos a continuación, se convertiría en el instrumento legislativo que permitió al Gobierno del Frente Popular reactivar la reforma.

\section{La reforma del Frente Popular: una oportunidad perdida}

Dice mucho de la lentitud e ineficacia de la reforma agraria ambicionada durante la Segunda República que no fuera hasta la primavera de 1936 cuando «empezó a cumplirse con ritmo de auténtica marcha» ${ }^{108}$. Efectivamente, solo a partir de entonces puede hablarse de la puesta en vigor de una verdadera reforma agraria que, por lo demás, y a pesar de estar concebida con mayor radicalismo, fue más racional e inteligente en la práctica, afectando a un menor número de propietarios que la ley de $1932^{109}$.

El programa del Frente Popular no incluia ninguna medida revolucionaria para resolver la cuestión agraria ${ }^{110}$. La principal diferencia entre los anteriores proyectos y los nuevos estribaba en que los últimos se aprobaron con rapidez y se pusieron en marcha con coherencia. Resulta asombroso observar los pocos reparos que encontró en las Cortes el

104 Ibidem, p. 9.448-9.450.

$105 \mathrm{Vid}$. la intervención de Claudio Sánchez-Albornoz y las reacciones de Gil-Robles, Martínez Barrio, Miguel Maura y Juan Ventosa, criticando la actitud de Izquierda Republicana, en ibidem, p. 9.440-9.447.

106 DSC, $\mathrm{n}^{\circ} 228,23$ de julio de 1935, p. 9.379-9.382.

$107 \mathrm{Vid}$. las intervenciones de ambos en $i$ bidem, p. 9.357-9.359 y 9.375-9.377, respectivamente.

108 Luis JimEnez de Asú A, La Constitución de la democracia española y el problema regional, Buenos Aires, Losada, 1946, p. 346.

109 Edward Malefakis, Reforma agraria, op. cit., p. 436.

110 El manifiesto electoral del Frente Popular fue publicado el 16 de enero de 1936 y se puede consultar en cualquier periódico de aquellas fechas. Asimismo, en Javier TuselL, Las elecciones del Frente Popular en España, vol. II, Madrid, Edicusa, 1971, p. 352-359 y Miguel ArTola, Partidos y programas politicos, 1808-1936. Tomo II: Manifiestos y programas politicos, Madrid, Aguilar, 1975, p. 454-459. El apartado tercero del programa estaba dedicado en su mayor parte a la cuestión agraria y reconocía, como luego apuntaremos, las diferencias existentes en el seno de la coalición. Tras la victoria en las elecciones, Azaña concretó ante las Cortes (DSC, $\mathrm{n}^{\circ} 17,15$ de abril de 1936, p. 286-287) los propósitos del Gobierno y anunció el envío inminente de cinco proyectos de ley (sobre derogación de la «contrarreforma» de 1935 y restitución de la Ley de Reforma Agraria de 1932, sobre devolución de bienes comunales a los municipios, sobre revisión de desahucios, sobre arrendamientos de fincas rústicas y sobre tierras procedentes de donaciones reales) y, para más adelante, la remisión de otros que contemplarían la creación de un Banco Agrario y la reorganización del crédito agrícola. En cumplimiento de este mensaje, Ruiz-Funes empezó a presentar ante la Cámara (DSC, aps. 5-9ªl n 19,17 de abril de 1936) los primeros proyectos solo dos días después. 
nuevo ministro de Agricultura, Mariano Ruiz-Funes (IR), cuando a finales de abril de 1936 presentó ante ellas sus planes. Los resultados fueron verdaderamente espectaculares: entre marzo y junio de 1936 se consiguió más que en los cinco años anteriores, con la distribución de medio millón de hectáreas entre unos cien mil campesinos ${ }^{111}$. Además, como reconoció el propio Ruiz-Funes en el Parlamento, el reparto masivo de tierras había sido posible gracias, en parte, a la aplicación del art. 27 de la muy conservadora ley de 1935, que como dijimos permitía las expropiaciones amparadas en motivos de «utilidad social» ${ }^{112}$.

Normalmente se ha aducido que si la política agraria se desarrolló enérgicamente en 1936 fue porque el escenario de tensión en el campo español, reflejado en las huelgas e invasiones espontáneas de fincas, así lo permitió. Aunque es innegable la influencia que ejercieron los paros y las ocupaciones, esta explicación es insuficiente, porque no explica las condiciones políticas en que se desenvolvieron las acciones de presión social y, tampoco, el apoyo que recibieron por parte de los órganos del Estado. $Y$ es que, por vez primera desde la proclamación de la Segunda República, la política agraria fue impulsada por un Gobierno cohesionado, sin contradicciones internas, en su programa de reformas sociales y económicas ${ }^{113}$. El bloque integrado por IR, UR y ERC, en torno al que se compondrían los Gabinetes de Manuel Azaña y Santiago Casares Quiroga, permitió una mayor coherencia en la acción gubernamental y un reforzamiento de los planteamientos reformistas dentro de las Cortes, lo que redundó en una mayor eficacia de las medidas legislativas.

La reforma agraria iniciada en 1936 no fue consecuencia de un previo pacto político ni de una transacción doctrinal entre los partidos integrados en el Frente Popular. De hecho, los republicanos de izquierda hicieron constar en el manifiesto electoral colectivo las diferencias de criterio que les separaban, en materia agraria, del PSOE ${ }^{114}$. Después, en las Cortes, ningún ministro expresaría ninguna objeción ideológica a los proyectos que se debatieron y tampoco a los fines que se querían alcanzar.

Malefakis ha apuntado que la normativa discutida por el Parlamento en 1936 no contempló muchos de los postulados doctrinales en boga durante la Legislatura Constituyente, que entonces parecían irrenunciables por la presencia del PSOE dentro del Gobierno y que terminarían conduciendo a la impotencia a aquel inicial programa reformista ${ }^{115}$. En esta ocasión, el ministro Ruiz-Funes excluyó de manera expresa la influencia socialista en sus planes y subrayó, por el contrario, el influyo de otro reformismo que se remontaba a las desamortizaciones: «Esta ley no es una ley marxista; ésta es una ley de reparación

111 Edward Malefakis, Reforma agraria, op. cit., p. 433. Vid. también Sergio Riesco, «La aceleración de la reforma agraria durante el Frente Popular», en Manuel Ballarín y José Luis Ledesma (coords.), La Repiblica del Frente Popular. Reformas, conflictos y conspiraciones, Zaragoza, Fundación Rey del Corral, 2010, p. 83-96.

112 «Si parece hecho por nosotros!», exclamó Ruiz-Funes (DSC, n 34, 27 de mayo de 1936, p. 921) al referirse a dicho artículo de la ley de 1936, que fue desarrollado a través de una serie de decretos dictados durante el mes de marzo de 1936.

113 Manuel RamíREZ, "La agregación de intereses», op. cit., p.32.

114 «Los republicanos no aceptan el principio de la nacionalización de la tierra y su entrega gratuita a los campesinos, solicitada por los delegados del Partido Socialista. Consideran convenientes las siguientes medidas, que se proponen la redención del campesino y del cultivador medio y pequeño, no solo por ser obra de justicia, sino porque constituyen la base más firme de reconstrucción económica nacional». Vid. Miguel ARTola, Partidos y programas, op. cit., p. 455.

115 Edward Malefakis, "The parties of the left and the Second Republic", en Raymond Carr (ed.), The Republic and the Civil War in Spain, London, Macmillan, 1971, p. 40. 
de una tradición, que nosotros entendemos conservar al restituir su viejo esplendor a los municipios y un ritmo de vida más elevado y más noble a la vida económica del país» ${ }^{116}$.

$\mathrm{Al}$ contrario, de lo que se trataba era de crear una amplia clase de pequeños propietarios agrarios, paso previo indispensable para culminar la revolución burguesa iniciada el siglo anterior y dar paso a una auténtica democratización del país ${ }^{117}$. Por eso, cualquier veleidad colectivizadora se abandonó en aras de la defensa y consolidación de una pequeña burguesía rural, llamada a ser el principal sostén de la República. Por eso, el ministro de Trabajo, Joan Lluhí, afirmaba: «Debo decir que, en tanto pueda yo influir en una obra de Gobierno, nada se hará que vaya en contra de los pequeños propietarios del campo. Yo no permito que se juegue con eso de que el Gobierno tolera que se vaya a una socialización. Eso es falso, porque si los propios socialistas ocuparan el poder, tampoco podrían hacer esa politica» ${ }^{118}$.

A la consistencia interna del discurso socio-económico manifestado por el Gobierno contribuyó en no poca medida el hecho de que el PSOE no tuviera carteras, a diferencia de 1931-1933. Las luchas entre las tendencias reformista y revolucionaria dentro del socialismo español prosiguieron en estas fechas, pero se desarrollaron en un marco extragubernamental $y$, por tanto, sin afectar a la estabilidad y cohesión del Gabinete. Tanto el partido como el sindicato socialista, PSOE y UGT, se dedicaron durante la primavera de 1936 a animar la presión en el campo, y no a contenerla, como había sucedido en el primer bienio, cuando estaban en el Gobierno. Incluso pudieron coordinarse con otros grupos obreros, como comunistas y anarquistas, dentro de una estrategia de acción común para el mundo agrario, lo cual habria sido imposible cuando los socialistas ocupaban responsabilidades en el Ejecutivo ${ }^{119}$. Por eso Ricardo Zabala, secretario general de la FNTT, pudo decir en el Parlamento que encabezaba un «grupo obrero» que aunaba a los diputados del PSOE y los del PCE (Partido Comunista de España), quienes compartian a este respecto una «identidad absoluta» de criterio ${ }^{120}$.

En el lado derecho del arco parlamentario, la oposición a la nueva reforma agraria tuvo un carácter distinto en 1936 al que había tenido en las Cortes Constituyentes. En general, se huyó del obstruccionismo y se abandonó la agresividad mostrada contra los proyectos anteriores. La reacción de Gil-Robles a las palabras de Azaña presentando los planes del Gobierno es muy ilustrativa: reconoció el fracaso de su partido en el terreno de las reformas sociales y económicas cuando estuvo en el poder y ofreció la colaboración de la CEDA al Gobierno, siempre y cuando éste no modificara su programa reformista ante las demandas del «bloque obrero»: «Para evitar injusticias sociales, para llegar a una más justa distribución de la riqueza, para acabar con esos desniveles [...] yo le digo que nuestros votos estarán a la disposición de S.S. [...] Lo que temo, señor Azaña, es que puesto S.S. a desarrollar ese programa tan nutrido de excelentes intenciones, tropiece con [...] la contradicción evidente entre el sentido que S.S. quiere imprimir a esa política y la trayectoria que quieren darla sus aliados circunstanciales de hoy» ${ }^{121}$.

116 DSC, $\mathrm{n}^{\circ} 58,8$ de julio de 1936, p. $1,972$.

117 Joaquin MAURin, Revolución y contrarrevolución en España, Paris, Ruedo ibérico, 1965, p. 58-59.

118 DSC, $\mathrm{n}^{\circ} 54,1$ de julio de 1936, p. 1.755.

119 Edward Malefakis, Reforma agraria, op. cit., p. 422-426.

$120 D S C, \mathrm{n}^{\circ} 54,1$ de julio de 1936, p. 1.736. Cuestión aparte era que dicho ("grupo obrero", de momento, se viera obligado a «atemperar su política en el orden agrario a las necesidades que le impone la alianza circunstancial con la burguesía liberal que forma con nosotros, en estos instantes, el Frente Popular».

121 DSC, $\mathrm{n}^{\circ} 17,15$ de abril de 1936, p. 298-299. 
Contribuyó a esta actitud de la CEDA el reforzamiento que dentro de este partido consiguió el sector socialcristiano tras las elecciones de febrero de 1936. Giménez Fernández ejerció un liderazgo tácito, a pesar de las reticencias ${ }^{122}$, y fue prácticamente el único portavoz de su partido en materia agraria en las Cortes, de manera que, durante la discusión de los proyectos de Ruiz-Funes, éste apenas encontró oposición entre los diputados cedistas. El propio Giménez Fernández diría estar en «un plan de leal colaboración, de leal aviso, no en un plan de obstrucción y de obstaculización a una obra que el Frente Popular estima necesaria $\rangle^{123}$.

La CEDA y los agrarios centraron sus ataques no en el contenido de las medidas reformadoras propuestas, que a menudo fueron pasadas por alto, sino en los desórdenes públicos y en la inseguridad que, consideraban, reinaba en el campo por el descontrol en la ocupación de las fincas ${ }^{124}$. Solo los diputados monárquicos y carlistas agrupados en torno al Bloque Nacional mostraron una oposición abierta a cualquier tipo de reforma agraria, ya que la consideraban la antesala de una revolución socialista dirigida contra la burguesía. Lo que su líder, José Calvo Sotelo, ofreció como alternativa no fue solo la monarquía, sino simple y llanamente el fascismo: «Esta es la raíz de la revolución fascista: la reacción de las clases medias, que no se resignan a ser proletarizadas, como lo están todos los habitantes de Rusia [...]. Por fortuna, señores -no os indignéis mucho-, no tendréis ocasión de ensayar vuestras especulaciones absurdas. ¡No os dejaremos! [...] Yo les digo a los agricultores españoles que la solución de sus problemas se logrará en un Estado corporativo» ${ }^{125}$.

En definitiva, fue en la primavera de 1936, y no antes, cuando pareció vislumbrarse la posibilidad de una verdadera reforma agraria, pues solo en ese momento se observó entre las fuerzas políticas presentes en las Cortes un clima propicio para que aquélla prosperara. La formación de un Gobierno homogéneo, compuesto exclusivamente por republicanos y dispuesto a llevar la iniciativa en materia socio-económica, fue un paso importante en la dirección reformista. Sin embargo, éste no dejaba de ser un Gabinete en minoría que, además, no agrupaba a todas las sensibilidades del reformismo. Aunque la guerra no lo hubiera desbaratado todo, el Gobierno habría estado necesitado de una ampliación de sus bases políticas, atrayéndose a los sectores que a ambos lados del espectro político compartian con él una posición reformadora. Esto habría supuesto la incorporación de ministros del grupo socialista que capitaneaba Indalecio Prieto y de los demócratascristianos de Giménez Fernández y Luis Lucia, y, de consuno, la escisión de los dos principales partidos de la Segunda República, el PSOE y la CEDA. Una posibilidad en absoluto descabellada, si se atiende a la complejidad interna de ambas organizaciones y a la dinámica política de aquellos días ${ }^{126}$.

En la primavera de 1936 se iniciaron contactos con el objetivo de formar un «Gobierno nacional» que abarcase desde el ala prietista del PSOE al ala más progresiva de la CEDA, pasando por los republicanos y los agrarios. Para llevar a buen puerto la formación de una fuerza parlamentaria suprapartidista, Luis Jiménez de Asúa, Jerónimo Bugeda y el propio Prieto, con el apoyo de Julián Besteiro, comenzaron a sondear a los diputados socialistas;

122 Los conflictos en el seno de la CEDA tras la derrota ante el Frente Popular pueden verse en Javier Tusell, Historia de la Democracia Cristiana, op. cit., vol. I, p. 334-362.

$123 D S C, \mathrm{n}^{\circ} 31,21$ de mayo de 1936 , p. 795.

124 El debate que provocó mayores enfrentamientos en el Parlamento durante aquellos meses tuvo lugar cuando el agrario José María Cid presentó una interpelación al Gobierno consensuada con todas las minorías de la derecha y que versaba sobre el problema del orden público en el campo. DSC, $n^{\circ} 54,1$ de julio de 1936, p. 1.743-1.753.

125 Ibidem, p. 1.775-1.776.

126 Manuel RAMírez, «La agregación de intereses», op. cit., p. 33. 
Miguel Maura, Claudio Sánchez-Albornoz y Felipe Sánchez-Román hicieron lo propio con los diferentes sectores republicanos; dentro de la CEDA actuaron Lucia y Giménez Fernández, mientras que en el PAE se confió en la capacidad de maniobra del ex ministro José María $\mathrm{Cid}^{127}$. Tras la escisión en la CEDA y el PSOE, habría una crisis en la que, según Sánchez-Albornoz, Azaña estaría conforme para solucionarla con un Gobierno presidido por Prieto ${ }^{128}$.

La precipitación de los acontecimientos hizo imposible, sin embargo, el éxito de la operación. Por un lado, Prieto temía que le consideraran un traidor y, cuando llegó la hora de la verdad, no se atrevió a asumir el riesgo de plantear la cuestión en la minoría socialista ${ }^{129}$. Aunque, según Giménez Fernández, en mayo de 1936 había pasado de 30 a 45 adeptos, todavía le faltaban 7 que no llegaron a decidirse a tiempo ${ }^{130}$. El desenlace en el seno del PSOE se aplazó hasta un Congreso extraordinario que se convocó para octubre de 1936, pero que nunca llegó a celebrarse. Giménez Fernández encontró también resistencias en su propio partido, sobre todo de Gil-Robles, que deseaba mantener a toda cosa la unidad de la CEDA ${ }^{131}$.

Al final, quienes tenían que haber dado los pasos trascendentales no los dieron, o por lo menos no a tiempo. Como escribió el socialista Rafael Méndez: «Si entonces hubiera roto Prieto con la disciplina del Partido Socialista habiendo capitaneado a sus disidentes y a una mayoría parlamentaria ansiosa de su liderazgo, se podría haber evitado la catástrofe de la guerra» ${ }^{132}$. El golpe de Estado de julio de 1936 convirtió la «operación Prieto» en una oportunidad perdida para salvar «aquella policéfala República» ${ }^{133}$ y redujo todo para protagonistas y estudiosos a un mero ejercicio de especulación contrafactual, desbordado ya el problema agrario y abarcando la Guerra civil.

127 Jesús PaBón, Cambó, 1876-1947, vol. III, Barcelona, Alpha, 1969, p. 480.

128 Claudio SÁnchez-Albornoz, Mi testamento histórico-politico, Barcelona, Planeta, 1975, p. 50.

129 Paul Preston, The Coming of the Spanish Civil War: Reform, Reaction and Revolution, London, Macmillan, 1978 , p. 361.

130 La opinión de Giménez Fernández aparece citada en una entrevista que recogió Carlos Seco Serrano, Historia de España. Tomo VI: Época contemporánea, Barcelona, Instituto Gallach, 1971, p. 164.

131 Vid. la versión de José María Gil-Robles, en No fue posible la paz, op. cit., p. 616-627. Según escribe Javier Tusell, (Historia de la Democracia Cristiana, op. cit., p. 357), el intento de Gil-Robles de preservar la cohesión de la CEDA, «aparte de difícil, resultaba contraproducente para la estabilidad del régimen».

132 Rafael MÉNDEz, «Memoria de Don Juan Negrín», en Índice, n² 298-300, 1971, p. 103. Sobre el encargo de Azaña a Prieto para la formación de Gobierno en mayo de 1936, y la renuncia de éste, ante un sector de su partido, vid. Juan Simeón Vidarte, Todos fuimos culpables, México, Fondo de Cultura Económica, 1973, p. 117-129; Santos JuliÁ, La izquierda del PSOE, op. cit., p. 95-108 y Octavio Cabezas, Indalecio Prieto. Socialista y español, Madrid, Algaba, 2005, p. 306-315.

133 Juan BeNET, Herrumbrosas lanzas. Libros VIII-XII, Madrid, Alfaguara, 1986, p. 49. 